\title{
Mg-Protoporphyrin IX Signals Enhance Plant's Tolerance to Cold Stress
}

\author{
Zhong-Wei Zhang ${ }^{1 * t}$, Zi-Li Wu ${ }^{2 t}$, Ling-Yang Feng ${ }^{1 t}$, Li-Hua Dong ${ }^{3 t}$, An-Jun Song', \\ Ming Yuan ${ }^{3}$, Yang-Er Chen ${ }^{3}$, Jian Zeng ${ }^{1}$, Guang-Deng Chen ${ }^{1}$ and Shu Yuan ${ }^{1 *}$

\begin{abstract}
${ }^{1}$ College of Resources, Sichuan Agricultural University, Chengdu, China, ${ }^{2}$ Key Lab of Aromatic Plant Resources Exploitation and Utilization in Sichuan Higher Education, College of Life Science and Food Engineering, Yibin University, Yibin, China,

${ }^{3}$ College of Life Sciences, Sichuan Agricultural University, Ya'an, China
\end{abstract}

\section{OPEN ACCESS}

Edited by:

John Love,

University of Exeter, UK

Reviewed by:

Uener Kolukisaoglu,

University of Tübingen, Germany

Aloysius Wong,

Kean University-Wenzhou, China

*Correspondence:

Zhong-Wei Zhang

zzwzhang@sicau.edu.cn

Shu Yuan

roundtree318@hotmail.com

${ }^{t}$ These authors have contributed equally to this work.

Specialty section: This article was submitted to Plant Physiology, a section of the journal Frontiers in Plant Science

Received: 15 March 2016 Accepted: 03 October 2016 Published: 18 October 2016

Citation:

Zhang Z-W, Wu Z-L, Feng L-Y,

Dong $L-H$, Song A-J, Yuan $M$, Chen $Y$ - $E$, Zeng J, Chen G-D and Yuan S (2016) Mg-Protoporphyrin IX Signals Enhance Plant's Tolerance to Cold Stress. Front. Plant Sci. 7:1545. doi: 10.3389/fpls.2016.01545
The relationship between Mg-protoporphyrin IX (Mg-Proto IX) signals and plant's tolerance to cold stress is investigated. Arabidopsis seedlings grown for 3 weeks were pretreated with $2 \mathrm{mM}$ glutamate (Glu) and $2 \mathrm{mM} \mathrm{MgCl}_{2}$ for $48 \mathrm{~h}$ at room temperature to induce Mg-Proto IX accumulation. Then cold stress was performed at $4^{\circ} \mathrm{C}$ for additional 72 h. Glu $+\mathrm{MgCl}_{2}$ pre-treatments alleviated the subsequent cold stress significantly by rising the leaf temperature through inducing Mg-Proto IX signals. The protective role of $\mathrm{Glu}+\mathrm{MgCl}_{2}$ treatment was greatly compromised in the mutants of Mg-Proto IX synthesis, Mg-Proto IX signaling, and cyanide-resistant respiration. And the enhancement of cold-responsive gene expression was greatly compromised in the mutants of Mg-Proto IX synthesis, Mg-Proto IX signaling and ABA signaling, but not in the mutant of cyanide-resistant respiration. Cold stress promoted cyanide-resistant respiration and leaf total respiration exponentially, which could be further induced by the $\mathrm{Glu}+\mathrm{MgCl}_{2}$ treatment. Mg-Proto IX signals also activate antioxidant enzymes and increase non-enzymatic antioxidants [glutathione but not ascorbic acid (AsA)] to maintain redox equilibrium during the cold stress.

Keywords: antioxidant enzyme, cold stress, cyanide-resistant respiration, glutathione, Mg-protoporphyrin IX signals

\section{INTRODUCTION}

Magnesium ( $\mathrm{Mg}$ ) is one of the essential macronutrients for plants. $\mathrm{Mg}$ is an irreplaceable constituent of the chlorophyll $(\mathrm{Chl})$ and regulates over 300 enzyme activities (especially for ATPases, protein kinases, glutathione synthase, phosphatases, and RNA polymerases), which are involved in ion absorption and transport (da Silva et al., 2014). Exogenous magnesium fertilizers increase crop yields. $\mathrm{Mg}^{2+}$ also has important roles in photosynthesis. Proton gradient is formed acorss the thylakoid lumen after the light perception and the electron transport, which results in charge separation and $\mathrm{Mg}^{2+}$ flux from lumen to the stroma (Maathuis, 2009).

$\mathrm{Mg}^{2+}$ is the cofactor of a large number of important enzymes and plays a key role in the stabilization of DNA and RNA. The most prominent example of enzyme reactions where $\mathrm{Mg}^{2+}$ is irreplaceable, are the processes associated with the phosphorylation-dephosphorylation cycle and energy transfer between ATP and ADP (Maathuis, 2009). 
Conjugated $\mathrm{Mg}$ is the best known for its central position in the $\mathrm{Chl}$ molecule where it covalently coordinates with four $\mathrm{N}$-atoms of the porphyrin ring. The enzyme of $\mathrm{Mg}^{2+}$ insertion into protoporphyrin is the Mg-chelatase (Maathuis, 2009). Among all kinds of Mg porphyrins, Mg-protoporphyrin IX (Mg-Proto IX, a $\mathrm{Chl}$ precursor) is a putative signaling molecule that accumulates in chloroplasts under stress conditions and regulates nuclear photosynthetic gene expression negatively (Zhang et al., 2011a,b).

Recent studies showed that Mg-Proto-IX-derived signals strongly regulate plant resistance to environmental stresses (Zhang et al., 2015). Mg-Proto IX signals promote stressresponsive gene expression after herbicide or high-light treatments (Zhang et al., 2011b). Transgenic rice expressing Myxococcus xanthus protoporphyrinogen oxidase (PPOX) accumulated Proto IX and Mg-Proto IX and had greater tolerance to drought stress than the wild-type plants (Phung et al., 2011). Rice coproporphyrinogen III oxidase mutant rlin1 (with less Mg-Proto IX accumulation) showed necrotic lesions on plant leaves (Sun et al., 2011).

GUN5 encodes the Mg-chelatase $\mathrm{H}$ subunit, the enzyme that introduces Magnesium ion into the porphyrin ring as a rate-limiting step of Chl biosynthesis (Strand et al., 2003). Plastid GUN1 (genomes uncoupled protein 1) and nuclear ABI4 (an Apetala 2-type ABA-insensitive transcription factor) are key factors in Mg-Proto IX signaling (Koussevitzky et al., 2007). ABI4 also is a key component of the ABA signaling pathway. Germination suppression sensitivity of gun4 and gun5 mutant seeds to ABA was increased compared to the wildtype seeds (Voigt et al., 2010). The gun1 mutant was more sensitive to ABA than the wild-type plants, implying that GUN1 participates in ABA signaling (Cottage et al., 2010). All of the data suggest that tetrapyrrole-plastid signals and $\mathrm{ABA}$ signals may be interconnected.

Mg-Proto-IX-synthesis mutant gun5 and Mg-ProtoIX-signaling mutants gun1 and abi4 had impaired basal high-temperature-tolerance (Miller et al., 2007) and coldtolerance (Tang et al., 2014). The gun5, gun1 and abi4 mutants had more oxidative damages than the wild-type plants under water stress (Cheng et al., 2011). The gun1 mutant had impaired drought-tolerance (Zhang et al., 2013). All of the studies indicated the physiological role of $\mathrm{Mg}$-Proto IX signaling in plant's stress adaption (Zhang et al., 2015).

The mitochondrial respiratory chain in higher plants consists of the ATP-coupling cytochrome pathway (CP) and the cyanide (CN)-resistant alternative respiratory pathway. The alternative pathway branches from the main respiratory electron transport chain after the site of ubiquinone pool, and bypasses the last few steps of the cytochrome respiratory pathway, where its terminal oxidase is the alternative oxidase (AOX) (Vanlerberghe and McIntosh, 1997). Early studies suggested that the alternative pathway consists in thermogenic tissues of plant, produces heat, and then induces florescence (Vanlerberghe and McIntosh, 1997). Moreover, AOX also scavenges reactive oxygen species (ROS) and enhances plant's cold-stress tolerance through thermogenesis (Tang et al., 2014).

Under the high-light stress, reducing equivalents (NADPH) from chloroplast are transported to mitochondrion by the malate/oxaloacetate shuttle and then dissipated mainly by the AOX. Thus, AOX plays a key role in chloroplast-mitochondria interactions (Zhang et al., 2016). AOX is encoded by a small nuclear multigene family that comprises at least two different subfamilies: $A O X 1$ and $A O X 2$. In Arabidopsis, five genes encoding the two subfamilies of $A O X$ have been identified, namely AOX1a, AOX1b, AOX1c, AOX1d, and AOX2. AOX1a is the major isoform in leaf and $60-70 \%$ of $C N$-resistant respiration is declined in the Arabidopsis aox1A mutant (Zhang et al., 2016). Furthermore, $A O X 1 a$ is a plastid-signal-inducible gene, which is positively regulated by the Mg-Proto IX accumulation (Zhang et al., 2011b), also indicating the chloroplast-mitochondria interaction.

In this study, we studied the relationship between plastid Mg-Proto IX signals and the cold stress tolerance with multiple Arabidopsis mutants. We found that cold-induced cyanideresistant respiration plays a dominate role in thermogenesis during the stress condition, which could be further promoted by the Mg-Proto IX signal. Mg-Proto IX signals also enhance antioxidant enzyme activities and accumulate non-enzymatic antioxidants (mainly glutathione) to maintain redox equilibrium during the cold stress.

\section{MATERIALS AND METHODS}

\section{Plant Materials and Growth Conditions}

gun5 and gun1 Arabidopsis mutant seeds were obtained from Prof. Joanne Chory (Salk Institute, La Jolla, CA, USA) and Dr. Enrique López-Juez (University of London, Egham, UK). Other Arabidopsis thaliana mutants were purchased from the Arabidopsis Biological Resource Center (Ohio State University, Columbus, OH, USA). Arabidopsis seedlings were grown in soil under a 16:8-h light-dark cycle of medium light $\left(100 \mu \mathrm{mol} \mathrm{m} \mathrm{m}^{-2} \mathrm{~s}^{-1}\right)$ at $25^{\circ} \mathrm{C}$ for 3 weeks.

\section{Magnesium Chloride, Glutamate, and Cold Treatments}

Three-weeks-old Arabidopsis seedlings were pretreated (sprayed on the leaves directly) with $2 \mathrm{mM}$ (or $8 \mathrm{mM}$ ) Glu, $2 \mathrm{mM}$ magnesium chloride $\left(\mathrm{MgCl}_{2}\right), 0.5 \mathrm{mM}$ Propyl gallate (PG, an inhibitor to cyanide-resistant respiration ( $\mathrm{Xu}$ et al., 2012) or water (for the untreated control) for $48 \mathrm{~h}$ (once a day) at the room temperature. After the pretreatments, cold stress was performed at $4 \pm 1^{\circ} \mathrm{C}$ for additional $72 \mathrm{~h}$.

\section{Chlorophyll and ALA Determination}

Chlorophyll contents were determined by using the equations: Chl $a(\mathrm{mg} / \mathrm{g})=\left[12.21 \times \mathrm{A}_{663}-2.81 \times \mathrm{A}_{646}\right] \times$ Volume $(80 \%$ acetone; $\mathrm{mL}) /[1000 \times$ Weight (tissue; g) $]$. Chl $b$ $(\mathrm{mg} / \mathrm{g})=\left[20.13 \times \mathrm{A}_{646}-5.03 \times \mathrm{A}_{663}\right] \times \mathrm{Volume} /(1000 \times$ Weight). Total Chls $(\mathrm{mg} / \mathrm{g})=\left[17.32 \times \mathrm{A}_{646}+7.18 \times \mathrm{A}_{663}\right] \times$ Volume/(1000 $\times$ Weight) (Lichtenthaler and Wellburn, 1983). The amount of formed 5-aminolevulinic acid 
(ALA) was measured according to the method of Dei (1985).

\section{Fluorescence HPLC Analysis of Proto IX and $\mathrm{Mg}$-Proto IX}

Pigments from $1 \mathrm{~g}$ seedlings were extracted with $2 \mathrm{ml}$ acetone: $0.2 \mathrm{M} \mathrm{NH}_{3} \cdot \mathrm{H}_{2} \mathrm{O}(9: 1, \mathrm{v} / \mathrm{v})$. The extracts were subjected to High Performance Liquid Chromatography (HPLC). 0-10.3 min eluate was detected with an excitation at $417 \mathrm{~nm}$ and an emission at $595 \mathrm{~nm}$, and then a change to $402 \mathrm{~nm}$ excitation and emission at $633 \mathrm{~nm}$ (Mock and Grimm, 1997; Mochizuki et al., 2008). Mixes of 1 pmol Mg-Proto IX and 1 pmol Proto IX were used as authentic standards.

\section{Arabidopsis Leaf Respiration Measurement}

A Clark electrode (Hansatech, King's Lynn, UK) was used. Arabidopsis leaves were cut into fine pieces, and then adjusted to approximately $2.5 \mathrm{mg}$ dry weight per $\mathrm{mL}$ before suspended in working buffer in the oxygen electrode cuvette. $1 \mathrm{mM} \mathrm{KCN}$ or $20 \mu \mathrm{M}$ PG was added to the buffer for CP inhibition and $\mathrm{CN}$-resistant pathway inhibition, respectively. $\mathrm{O}_{2}$ uptake value in the presence of $\mathrm{KCN}$ but sensitive to $\mathrm{PG}$ indicates the $\mathrm{CN}$-resistant respiration capacity. While the $\mathrm{O}_{2}$ uptake value without KCN or PG indicates the total respiration (Lei et al., 2008).

\section{Measurement of $\mathrm{CO}_{2}$ Assimilation Rate}

An open photosynthesis system TPS-1 (PP systems, Hitchin, UK) was used. $\mathrm{CO}_{2}$ assimilation rate $(P \mathrm{n})$ was measured at $360 \mu \mathrm{mol}$ $\mathrm{mol}^{-1} \mathrm{CO}_{2}$ concentration and illumination of $0-1600 \mu \mathrm{mol} \mathrm{m}^{-2}$ $\mathrm{s}^{-1}$ at $25^{\circ} \mathrm{C}$ (Liu et al., 2009; Chen et al., 2015).

\section{Determination of Antioxidant Enzymes}

For determination of antioxidant enzymes, $0.3 \mathrm{~g}$ of Arabidopsis leaf were grounded in $3 \mathrm{~mL}$ extraction buffer containing $25 \mathrm{mM}$ Hepes, 2\% polyvinyl-pyrrolidone (PVP), $0.2 \mathrm{mM}$ EDTA and $2 \mathrm{mM}$ ascorbate $(\mathrm{pH}$ 7.8). After $20 \mathrm{~min} 12,000 \times g$ centrifugation at $4^{\circ} \mathrm{C}$, the supernatants were collected (Cao et al., 2009). Ascorbate peroxidase (APX), superoxide dismutase (SOD), glutathione reductase (GR), peroxidase (POD), and dehydroascorbate reductase (DHAR) activities were determined (Cao et al., 2009). The SOD assay buffer contains $50 \mathrm{mM}$ phosphate, $12 \mathrm{mM}$ L-methionine, $0.1 \mathrm{mM}$ EDTA, $75 \mu \mathrm{M}$ nitro blue tetrazolium (NBT) and $2 \mu \mathrm{M}$ riboflavin $(\mathrm{pH}$ 7.8). Reaction condition was $15 \mathrm{~min}$ light of $50 \mu \mathrm{mol}$ $\mathrm{m}^{-2} \mathrm{~s}^{-1}$ with simultaneous shaking. Then the $\mathrm{OD}_{560}$ was detected. The POD assay buffer contains $50 \mathrm{mM}$ phosphate, buffer, $40 \mathrm{mM} \mathrm{H} \mathrm{H}_{2} \mathrm{O}_{2}$ and $10 \mathrm{mM}$ guaiacol ( $\mathrm{pH}$ 7.0). Then the $\mathrm{OD}_{470}$ was detected at $20^{\circ} \mathrm{C}$. The APX assay buffer contains $0.1 \mathrm{mM}$ EDTA, $50 \mathrm{mM}$ Hepes- $\mathrm{KOH}, 0.2 \mathrm{mM}$ $\mathrm{H}_{2} \mathrm{O}_{2}$ and $0.5 \mathrm{mM}$ AsA ( $\mathrm{pH}$ 7.6). Then the $\mathrm{OD}_{290}$ was detected. Reduced ascorbic acid/dehydroascorbate (AsA/DHA) and reduced glutathione/oxidized glutathione (GSH/GSSG) and ratios were determined as indicated previously. GR assay buffer contains $1 \mathrm{mM}$ EDTA, $100 \mathrm{mM}$ Tris- $\mathrm{HCl}, 0.2 \mathrm{mM}$ NADPH, and1 mM GSSG ( $\mathrm{pH} 8.0$ ). Then the $\mathrm{OD}_{340}$ was detected. DHAR assay buffer contains $1 \mathrm{mM}$ EDTA, $100 \mathrm{mM}$ Hepes-KOH, $0.2 \mathrm{mM}$ DHAR, and $2.5 \mathrm{mM}$ GSH (pH 7.0). Then the $\mathrm{OD}_{265}$ was detected (Cao et al., 2009; Chen et al., 2015).

\section{Hydrogen Peroxide and Superoxide Staining and Quantification}

Hydrogen peroxide and superoxide in leaves were visualized by 3,3-diaminobenzidine (DAB) and NBT, respectively. Arabidopsis leaves were cut at the leaf base and infiltrated in $0.5 \mathrm{mg} \mathrm{mL}^{-1}$ NBT or $2 \mathrm{mg} \mathrm{mL}^{-1} \mathrm{DAB}$ solution for $2-8 \mathrm{~h}$. Samples were then decolorized in $95 \%$ ethanol at $80^{\circ} \mathrm{C}$ for $0.5-2 \mathrm{~h}$ (Yang et al., 2004).

$\mathrm{H}_{2} \mathrm{O}_{2}$ content was measured as described by Velikova et al. (2000). Approximately $0.5 \mathrm{~g}$ leaves were homogenized in ice bath with $5 \mathrm{~mL} 0.1 \%(\mathrm{~m} / \mathrm{v})$ trichloroacetic acid (TCA). The homogenate was centrifuged at $12,000 \times g$ for $20 \mathrm{~min}$ at $4^{\circ} \mathrm{C}$, $0.5 \mathrm{~mL}$ of the supernatant was added to $0.5 \mathrm{~mL}, 10 \mathrm{mM}$ potassium phosphate buffer (pH 7.0) and $1 \mathrm{~mL} 1 \mathrm{M} \mathrm{KI}$. The absorbance of supernatant was read at $390 \mathrm{~nm}$.

Superoxide was quantitated by the hydroxylamine method (Elstner and Heupel, 1976). $1 \mathrm{~g}$ tissue was homogenized in $65 \mathrm{mM}$ potassium phosphate buffer $(3 \mathrm{~mL} ; \mathrm{pH}$ 7.8). The homogenate was centrifuged at $(10,000 \times g$ for $15 \mathrm{~min})$. The supernatant $(0.5 \mathrm{~mL})$ was added to $65 \mathrm{mM}$ potassium phosphate buffer $(0.5 \mathrm{~mL}$; pH 7.8) containing $10 \mathrm{mM}$ hydroxylammoniumchloride $(0.1 \mathrm{~mL})$ and incubated $\left(25^{\circ} \mathrm{C}\right.$ for $\left.20 \mathrm{~min}\right)$. Sulphanilic acid $(58 \mathrm{mM} ; 1 \mathrm{~mL})$ and $\alpha$-naphthyl amine $(7 \mathrm{mM} ; 1 \mathrm{~mL})$ were added to the mixture, and it was allowed to incubate $\left(25^{\circ} \mathrm{C}\right.$ for $20 \mathrm{~min}$ ). The final solution was mixed with an equal volume of chloroform and the absorbance of the pink phase was measured at $530 \mathrm{~nm}$.

\section{RWC and MDA Content Measurements}

Relative water content (RWC) is defined as the following equation: $\mathrm{RWC}=($ fresh weight - dry weight $) /($ turgid weight dry weight) $\times 100 \%$.

Leaf malonyldialdehyde (MDA) level was detected as described previously. About $0.2 \mathrm{~g}$ Arabidopsis leaves were grounded in $5 \mathrm{~mL}$ ice-cold 5\% TCA. After $10 \mathrm{~min} 8,000 \times g$ centrifugation at $4^{\circ} \mathrm{C}$, supernatant was transferred into a new EP tube and then 20\% TCA with $0.5 \%$ thiobarbituric acid (TBA) was added. The mixture was boiled for $0.5-1 \mathrm{~h}$, and then $10 \min 8,000 \times g$ centrifugation was performed. OD values $\left(\mathrm{OD}_{535}-\mathrm{OD}_{600}\right)$ of the supernatant were measured. The extinction coefficient is $155 \mathrm{mM}^{-1} \mathrm{~cm}^{-1}$ (Cao et al., 2009).

\section{Measurement of Leaf Temperature}

Arabidopsis leaf temperature was visualized by a FLIR T620 thermal-imaging camera (Thermal CAM-FLIR Systems, USA). Individual pot was transferred from the $4^{\circ} \mathrm{C}$ cabinet to the room temperature. Then within $60 \mathrm{~s}$ after the transfer (about 45-60 s), the thermal-photo was taken. The thermal image was analyzed by the software accompanying with the camera. Average leaf temperatures based on the leaf area are shown. 
A

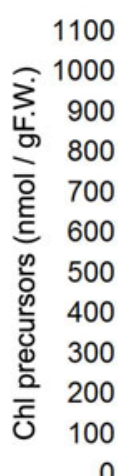

B

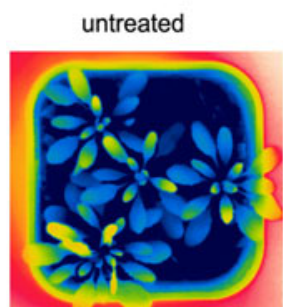

$12 \pm 2^{\circ} \mathrm{C}^{\mathrm{a}}$

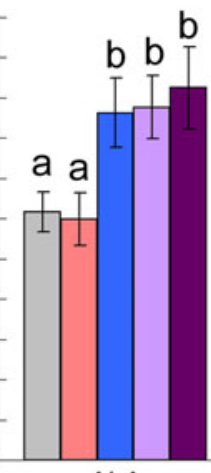

ALA $\square$ untreated

$\square 2 \mathrm{mM}$ Glu

$\square 2 \mathrm{mM} \mathrm{MgCl}_{2}+8 \mathrm{mM} \mathrm{Glu}$ $\square 2 \mathrm{mM} \mathrm{MgCl}_{2}$

$\square 2 \mathrm{mM} \mathrm{MgCl}_{2}+2 \mathrm{mM} \mathrm{Glu}$

\begin{abstract}
$2 \mathrm{mM} \mathrm{MgCl} 2$
\end{abstract}

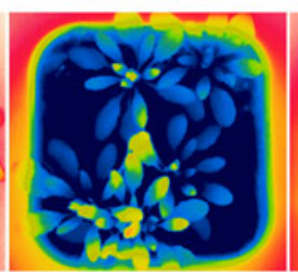

$13 \pm 2^{\circ} \mathrm{C}^{\mathrm{a}}$

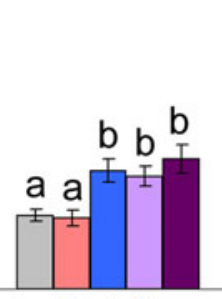

ProtolX

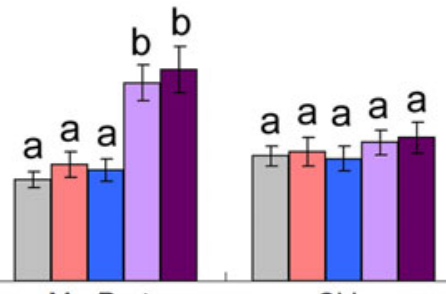

Chla

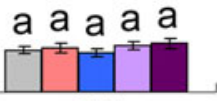

Chlb

FIGURE 1 | Effects of 2 or $8 \mathrm{mM}$ glutamate (Glu) $+2 \mathrm{mM} \mathrm{MgCl}_{2}$ pre-treatments on Mg-Proto IX and chlorophyll (Chl) synthesis at room temperature (A) and leaf temperature after the subsequent cold stress (B). After the pretreatments with Glu and $\mathrm{MgCl}_{2}$ for $48 \mathrm{~h}$ at the room temperature, cold stress was performed at $4 \pm 1{ }^{\circ} \mathrm{C}$ for additional $72 \mathrm{~h}$. Levels of Chl precursors ALA, Proto IX, and Mg-Proto IX in 21-day wild-type Arabidopsis seedlings were determined (A). F.W., fresh weight. Error bars show standard deviations $(n=3)$. Arabidopsis leaf temperature was visualized by a FLIR T620 thermal-imaging camera. Average leaf temperatures based on the leaf area are shown below corresponding thermal images (B). Multiple comparisons using the least significant difference (LSD) method, uppercase letters represent a significant level of 0.05 . With the same letter are not significantly different between the treatments.

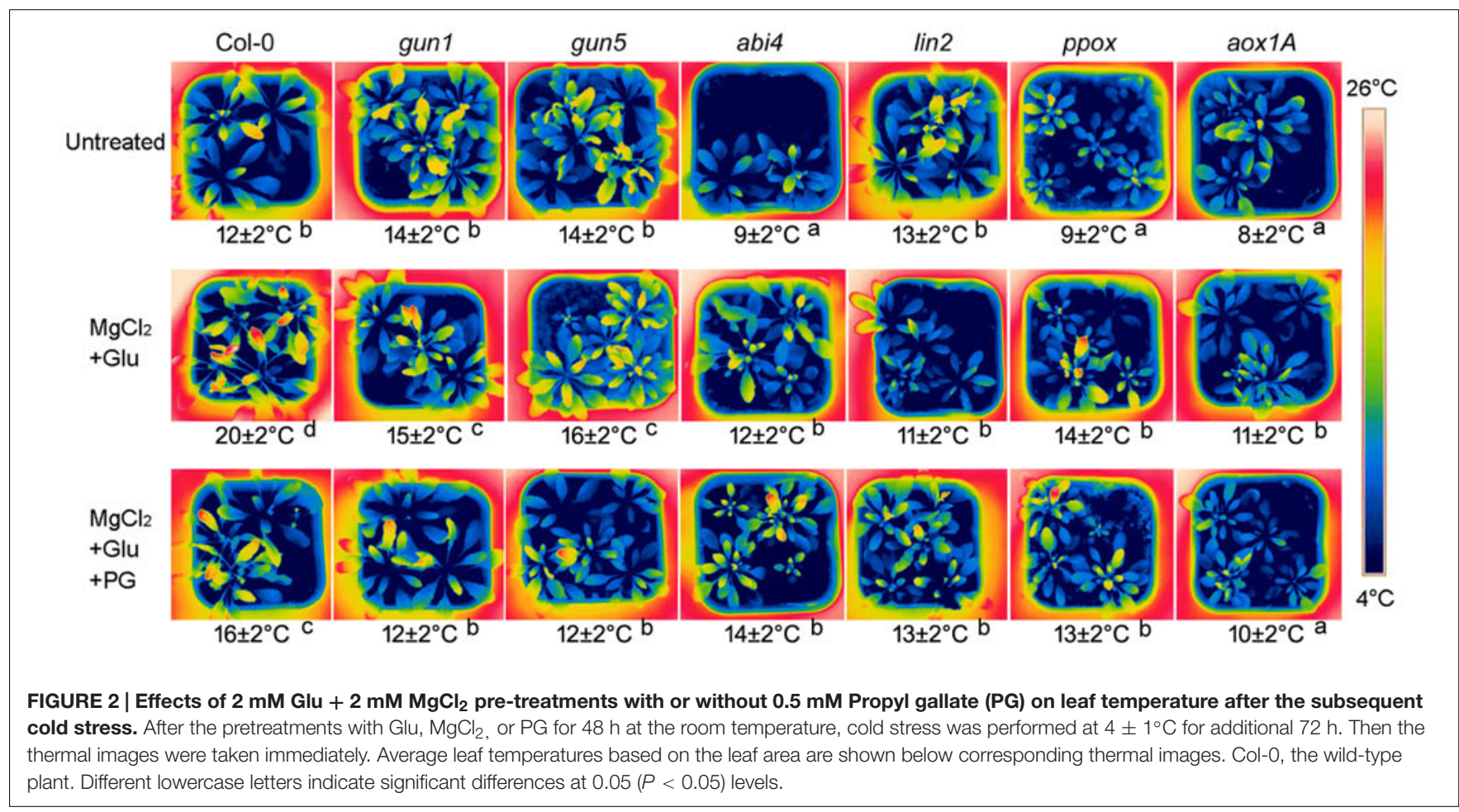




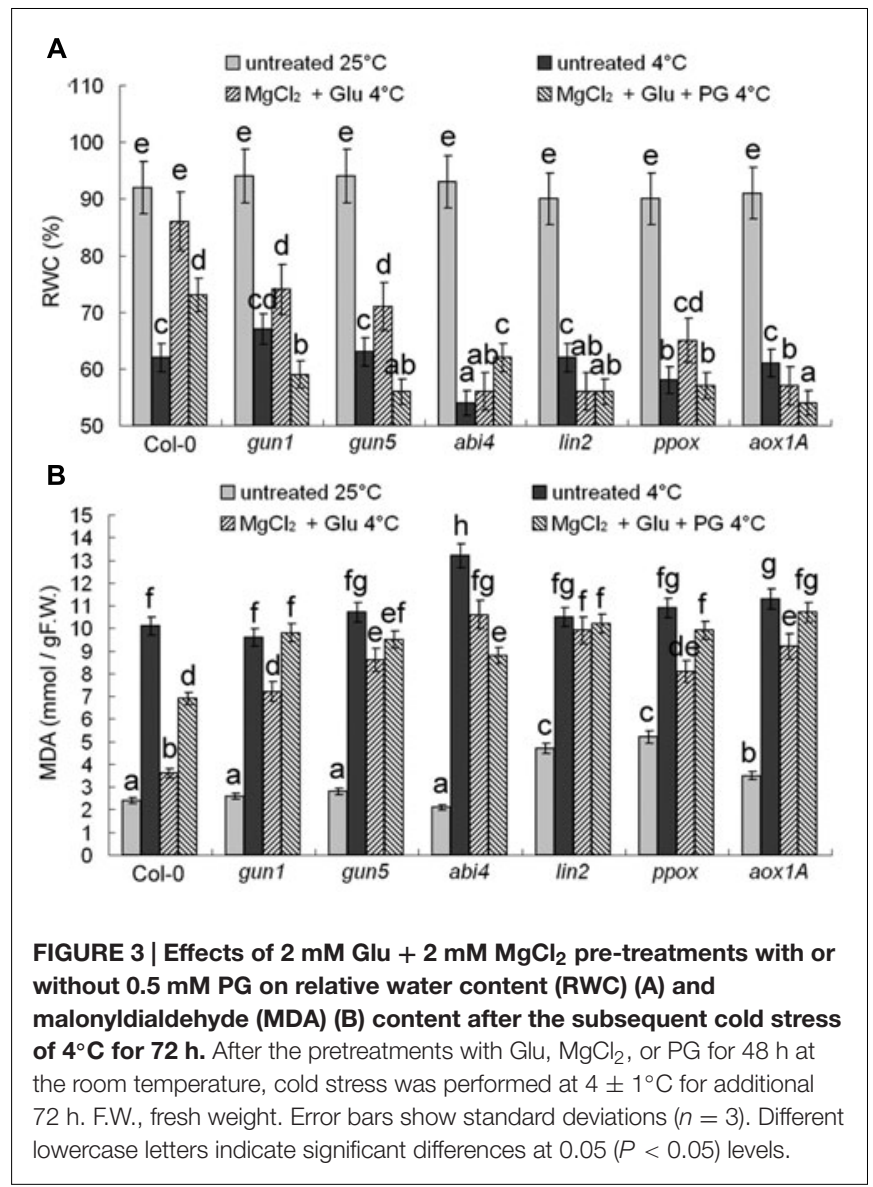

\section{RNA Isolation, cDNA Synthesis, and qPCR}

RNA was isolated simultaneously with the TRIzol RNA kit (Invitrogen, Carlsbad, CA, USA). RNA The purification of RNA samples was detected by measuring the absorbance ratios of $\mathrm{A}_{260} / \mathrm{A}_{280}$, which in all the samples were about 1.9. cDNA was synthesized from RNA templates following the SYBR Premix Ex Taq (TaKaRa, Dalian, China) protocol. The primers used for qPCR are same as in Park et al. (2015). qPCR was performed with SYBR-Green chemistry using the Eppendorf Realplex Mastercycler. The Ct (threshold cycle), defined as the PCR cycle at which a statistically significant increase of reporter fluorescence was first detected, was used as a measure for the starting copy numbers of the target gene (Czechowski et al., 2005; Yuan et al., 2016). Three technical replicates were performed for each experiment. ACTIN1 gene (At2g37620) was used as internal controls.

\section{Western Blotting to CBF1 Protein}

SDS - polyacrylamide gel electrophoresis (SDS-PAGE) and Western blotting analysis of the extracts were processed according to the method as described previously (Zhang et al., 2013; Yuan et al., 2016). Leaf total protein extracts $(20 \mu \mathrm{g})$ were loaded in each lane. For Western Blotting, the proteins were electron-transferred onto nitrocellulose films. Antibodies used

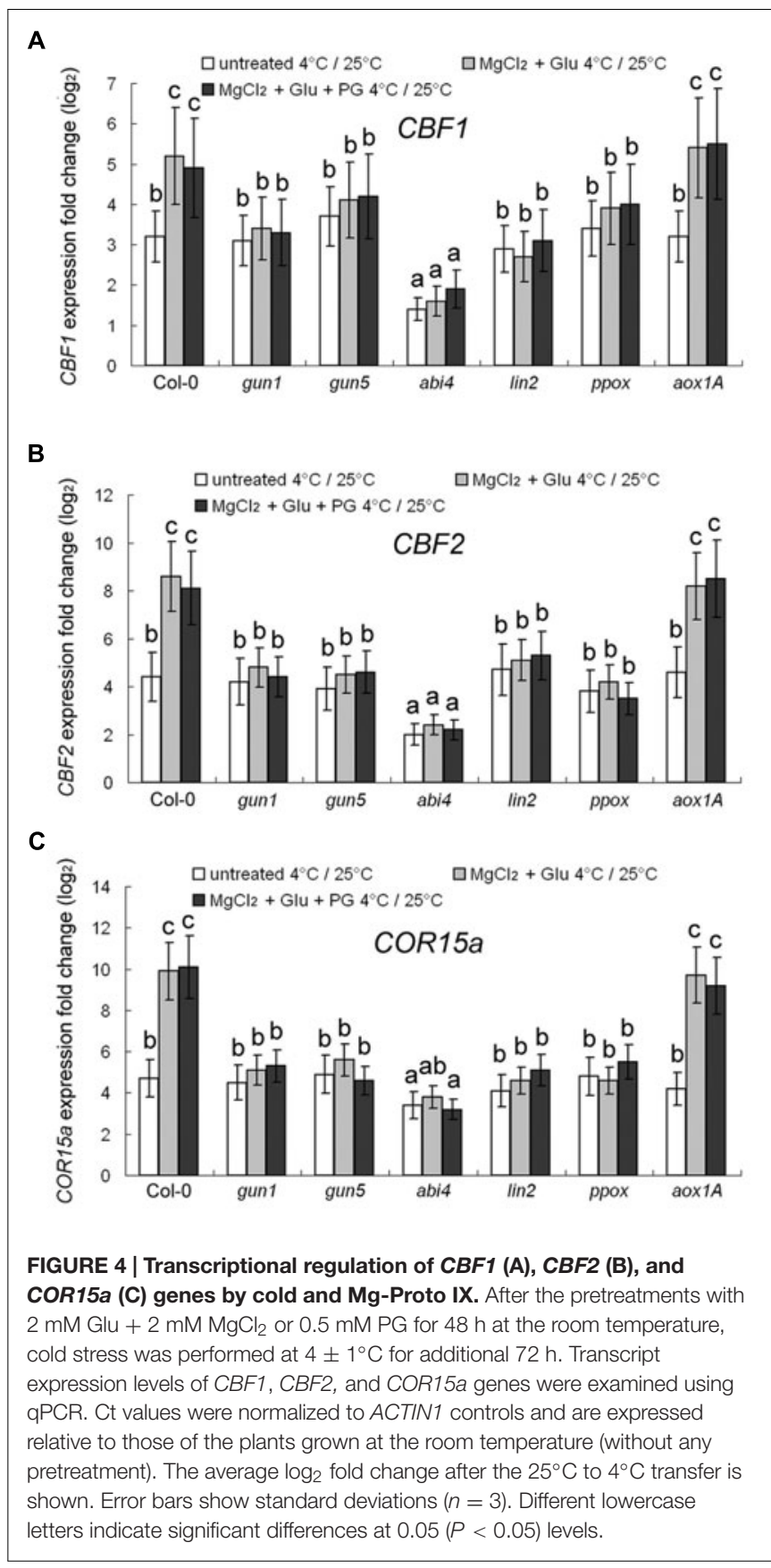

were anti-tumidinoda CBF1 (a gift from Dr. Qibing Chen at Sichuan Agricultural University) and anti-Arabidopsis ACTIN1 IgG (AgriSera Comp., Umea, Sweden). Alkaline phosphataseconjugated antibodies were used as the secondary antibodies.

\section{Statistics Analysis}

Three to five rosette seedlings were collected for each treatment. The typical results are shown as mean values of three biological replicates with standard deviations $( \pm \mathrm{SD})$. The Student's $t$-test was performed for all the data. Significant differences were identified with the $p$-value of 0.05 . 


\section{RESULTS}

\section{Effects of Glutamate $+\mathrm{MgCl}_{2}$ Pre-treatments on Mg-Proto IX Levels and Leaf Temperatures}

Considering the possible relationship between Mg-Proto IX signaling and cold-stress tolerance mentioned above (Tang et al., 2014), we used some chemical pre-treatments to trigger MgProto IX signals before the cold stress onset. One molecule of Mg-Proto IX comes from four molecules of Glu and one molecule of magnesium ion. Therefore, we used $8 \mathrm{mM}$ Glu and $2 \mathrm{mM}$ magnesium chloride to induce Mg-Proto IX accumulation. However, from Figure 1A, we know that $8 \mathrm{mM} \mathrm{Glu}+2 \mathrm{mM}$ $\mathrm{MgCl}_{2}$ and $2 \mathrm{mM} \mathrm{Glu}+2 \mathrm{mM} \mathrm{MgCl} 2$ had a similar effect on Mg-Proto IX synthesis (the difference was not significant, $p>0.05$ ). While solo magnesium chloride treatment or solo Glu treatment could not induce Mg-Proto IX accumulation, although solo Glu treatment apparently induced 5-aminolevulinic acid (ALA) accumulation. Therefore, the concentration of $2 \mathrm{mM}$ Glu was selected for further studies.

Mg-Proto IX accumulation did not induce apparent temperature rising under the normal growth condition of the room temperature (increasing extent $<3^{\circ} \mathrm{C}$; data not shown). However, $\mathrm{Glu}+\mathrm{MgCl}_{2}$ pre-treatments alleviated the subsequent cold stress significantly by rising the leaf temperature (about $8^{\circ} \mathrm{C}$ higher than the control). $8 \mathrm{mM} \mathrm{Glu}+2 \mathrm{mM} \mathrm{MgCl}_{2}$ and $2 \mathrm{mM}$ $\mathrm{Glu}+2 \mathrm{mM} \mathrm{MgCl}_{2}$ had a similar effect on leaf temperature (the difference was not significant, $p>0.05$ ). While solo magnesium chloride treatment or solo Glu treatment could not induce leaf temperature enhancement (Figure 1B).

\section{The Protective Role of Glutamate $+\mathrm{MgCl}_{2}$ Treatments on Cold-Stress}

Glutamate $+\mathrm{MgCl}_{2}$-induced leaf temperature enhancement was greatly compromised in Arabidopsis Mg-chelatase $\mathrm{H}$ subunit mutant (gun5), protoporphyrinogen oxidase mutant (ppox) and coproporphyrinogen III oxidase mutant (lin2), all of which accumulate less $\mathrm{Mg}$-Proto IX than the wild-type. $\mathrm{Glu}+\mathrm{MgCl}_{2}$ treatment also could not prompt leaf temperature of gun 1 and abi4 mutants, whose Mg-Proto IX signaling is blocked (Figure 2).

At $28^{\circ} \mathrm{C}$, Arabidopsis plants exhibit longer petioles, larger leaves and have faster growth and development compared to those grown at 21 degrees. Glu $+\mathrm{MgCl}_{2}$ treatment at $21^{\circ} \mathrm{C}$ resulted in similar phenotypic effects of $28^{\circ} \mathrm{C}$. While the increasing of leaf area and seedling fresh weight was greatly compromised in the mutants of Mg-Proto IX synthesis or Mg-Proto IX signaling (Supplementary Figure S1). These data confirmed the role of Mg-Proto IX in cold stress tolerance.

Our previous study showed that among stress-responsive genes, the AOX gene AOX1a was prominently induced by $\mathrm{Mg}$ Proto IX signals (Zhang et al., 2011b). AOX is a key enzyme of CN-resistant respiration, which process produces heat, especially under the cold stress or during the flowering for volatilizing scents (Vanlerberghe and McIntosh, 1997; Seymour and Gibernau, 2008). Therefore, the role of CN-resistant respiration
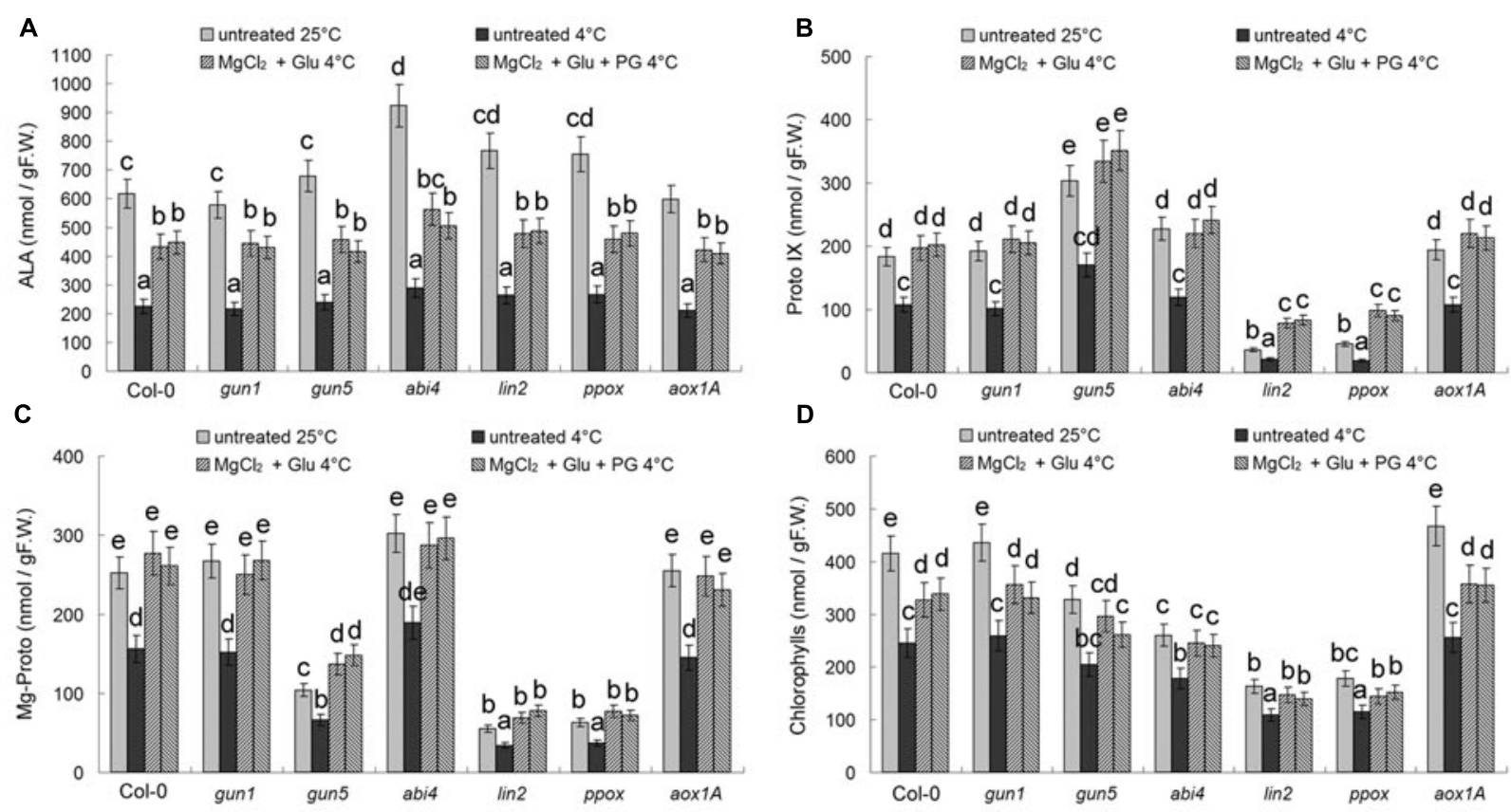

FIGURE 5 | Effects of $2 \mathrm{mM}$ Glu $+2 \mathrm{mM} \mathrm{MgCl} 2$ pre-treatments with or without $0.5 \mathrm{mM}$ PG on Chls and their three precursors after the subsequent cold stress. After the pretreatments with Glu, $\mathrm{MgCl}_{2}$, or PG for $48 \mathrm{~h}$ at the room temperature, cold stress was performed at $4 \pm 1{ }^{\circ} \mathrm{C}$ for additional $72 \mathrm{~h}$. Levels of Chl precursors ALA (A), Proto IX (B), Mg-Proto IX (C), and seedling total Chls (D) were determined. F.W., fresh weight. Error bars show standard deviations $(n=3)$. Different lowercase letters indicate significant differences at $0.05(P<0.05)$ levels. 
A

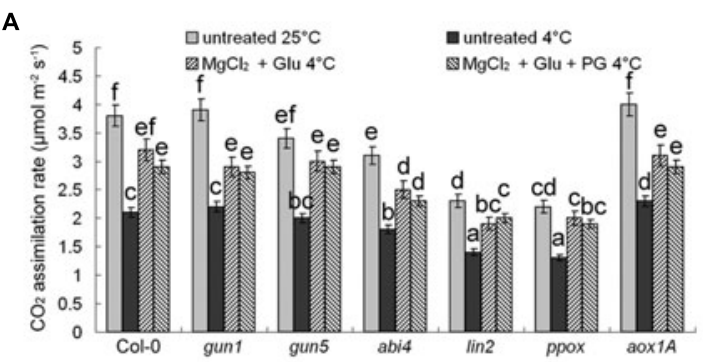

B

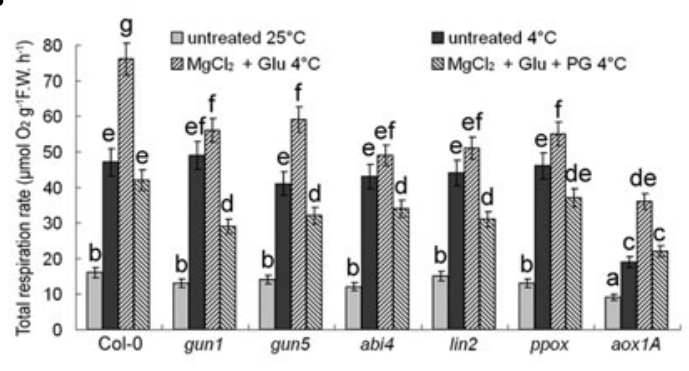

C

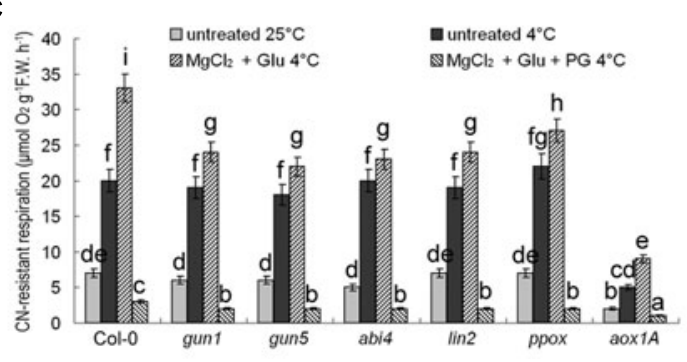

FIGURE 6 | Effects of $2 \mathrm{mM}$ Glu $+2 \mathrm{mM} \mathrm{MgCl}_{2}$ pre-treatments with or without $0.5 \mathrm{mM} \mathrm{PG}$ on $\mathrm{CO}_{2}$ assimilation rate (A), $\mathrm{CN}$-resistant respiration rate $(\mathrm{B})$, and leaf total respiration rate $(\mathrm{C})$ after the subsequent cold stress. After the pretreatments with $\mathrm{Glu}, \mathrm{MgCl}_{2}$, or $\mathrm{PG}$ for $48 \mathrm{~h}$ at the room temperature, cold stress was performed at $4 \pm 1^{\circ} \mathrm{C}$ for additional 72 h. F.W., fresh weight. Error bars show standard deviations $(n=3)$. Different lowercase letters indicate significant differences at 0.05 $(P<0.05)$ levels.

in Mg-Proto-IX-induced leaf temperature enhancement was investigated further. Leaf temperatures were always low in aox $1 \mathrm{~A}$ mutant or in the seedlings treated with PG (an inhibitor to CNresistant respiration), no matter with or without $\mathrm{Glu}+\mathrm{MgCl}_{2}$ pre-treatments (Figure 2), suggesting the dominated role of CN-resistant respiration in Mg-Proto-IX-mediated cold tolerance.

Changes of RWC and MDA content (Figure 3) confirmed that the protective role of $\mathrm{Glu}+\mathrm{MgCl}_{2}$ treatments was greatly compromised in all the mutants of Mg-Proto IX synthesis, MgProto IX signaling, or CN-resistant respiration.

\section{Mg-Proto IX Signaling Enhances Cold Tolerance by Inducing Cold-Responsive Gene Expression}

Expression of three cold-responsive genes was investigated. C-repeat Binding Factors (CBF) 1 and 2 (Park et al., 2015) and Cold-Regulated protein COR15a (a 15-kDa polypeptide targeted to the chloroplast; Steponkus et al., 1998) are coldresponsive marker proteins. $72-\mathrm{h} 4^{\circ} \mathrm{C}$ cold-stress induced 3.2-fold, 4.4-fold and 4.7-fold increasing of CBF1, CBF2, and COR15a transcripts, respectively, compared to the control seedlings grown at $25^{\circ} \mathrm{C}$ (Figure 4). However, the cold-induced gene-expression enhancement was largely compromised in abi4 mutant ( $A B A$ Insensitive 4), but not in other mutants, implying that ABA signaling may also participate in cold-stress responses. The cold-responsive gene expression could be further promoted by the $\mathrm{Glu}+\mathrm{MgCl}_{2}$ treatment. However, this effect has not been observed for all the mutants of Mg-Proto IX synthesis or $\mathrm{Mg}$ Proto IX signaling (Figure 4), also indicating the key role of Mg-Proto-IX signaling in cold-stress tolerance. PG treatments barely affected cold-responsive gene expression (Figure 4).

To be more convincing, western blot analysis to CBF1 protein was performed. Changes at the translational level were consistent with those at the transcriptional level (Supplementary Figure S2), which excluded the secondary co-regulatory effects of cold stress at the post-transcriptional level.

\section{Effects of Cold Stress and Glutamate $+\mathrm{MgCl}_{2}$ Treatments on Chlorophyll Synthesis}

Cold stress led to suppression of Chl synthesis. Chls and all Chl precursors (ALA, Proto IX, and Mg-Proto IX) decreased obviously after the cold stress (Figure 5). Glu $+\mathrm{MgCl}_{2}$ treatments induced $\mathrm{Mg}$-Proto IX accumulation significantly, as well as ALA, Proto IX and Chls, therefore offsetting the effect of cold stress on Chl synthesis. Because of the mutations in Chl biosynthesis enzymes, Proto IX levels were greatly reduced in lin2 and ppox mutants, and Mg-Proto IX levels were greatly reduced in gun5, lin2, and ppox mutants. As mentioned above, $\mathrm{PG}$ is a CN-resistant respiration specific inhibitor, and thus did not affect Chl levels or the precursor levels (Figure 5).

\section{Effects of Cold Stress and Glutamate $+\mathrm{MgCl}_{2}$ Treatments on Carbon Assimilation and Dissimilation}

$\mathrm{CO}_{2}$ assimilation rates were positively related with their Chl levels (decreased after cold stress, but increased by the Glu $+\mathrm{MgCl}_{2}$ treatment; Figure 6A). On the contrary, cold stress promoted $\mathrm{CN}$-resistant respiration and total respiration exponentially, which could be further induced by the $\mathrm{Glu}+\mathrm{MgCl}_{2}$ treatment. While $\mathrm{PG}$ or mutation in AOX1a gene effectively inhibited $\mathrm{CN}$-resistant respiration (Figures 6B,C). Induction of $\mathrm{CN}$-resistant respiration by the $\mathrm{Glu}+\mathrm{MgCl}_{2}$ treatment was greatly compromised in all the mutants of Mg-Proto IX synthesis and $\mathrm{Mg}$ Proto IX signaling (Figures 6B,C), indicating the role of Mg-Proto IX signaling in $\mathrm{CN}$-resistant respiration enhancement. 


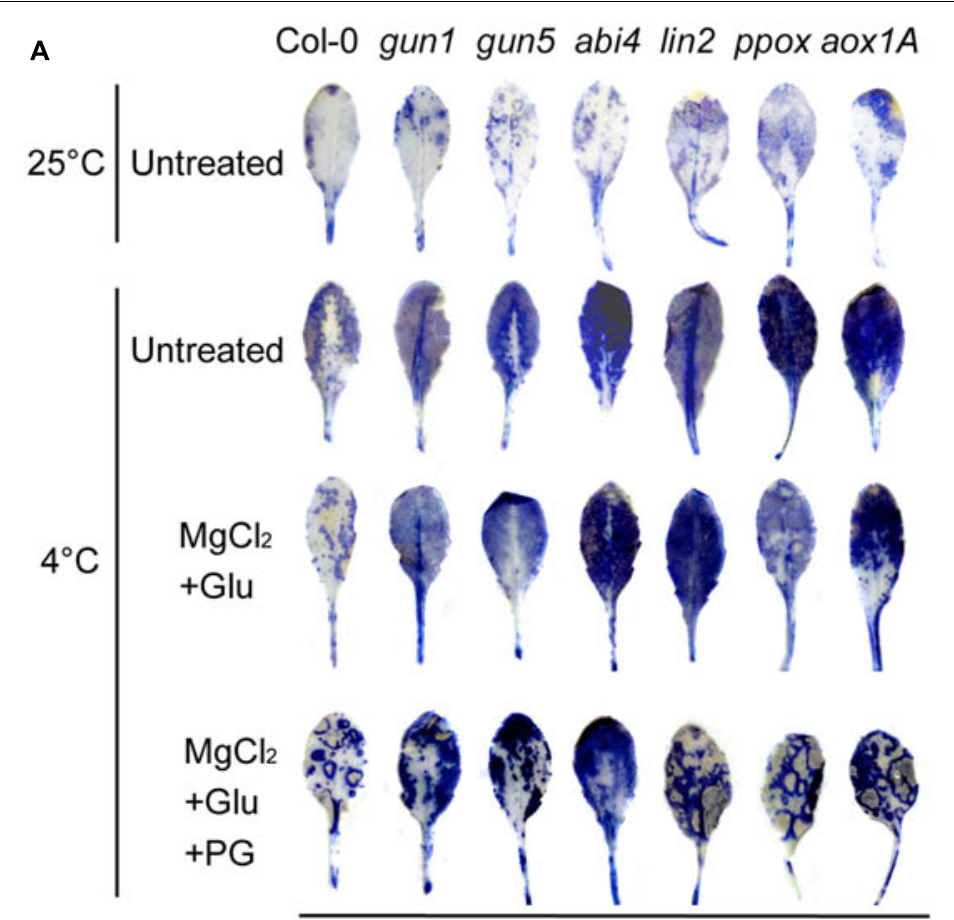

B
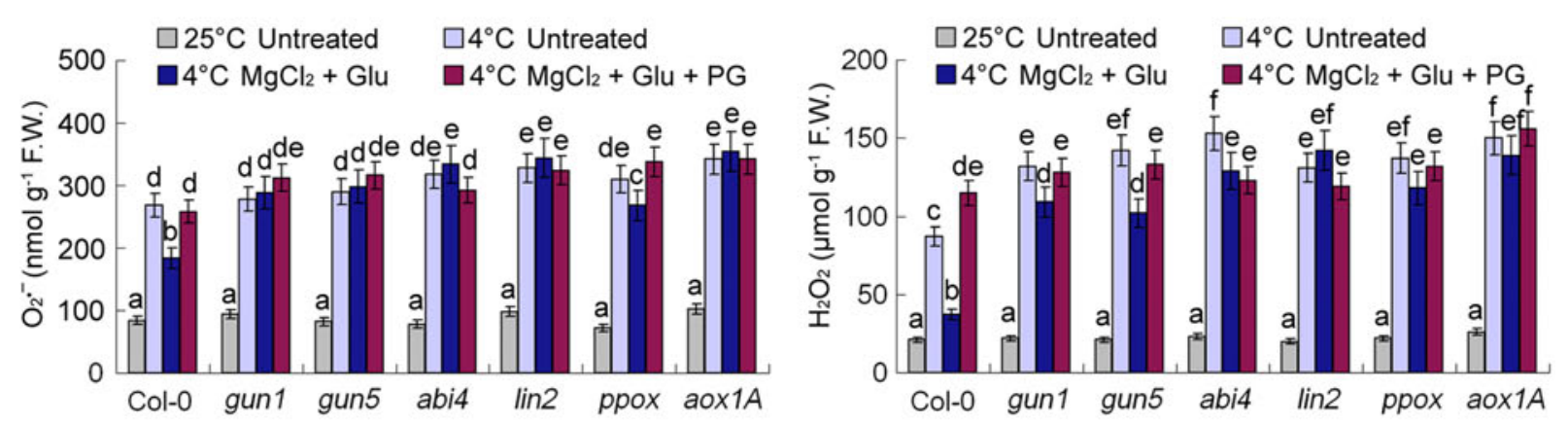

FIGURE 7 | Superoxide and $\mathrm{H}_{2} \mathrm{O}_{2}$ staining of leaves pre-treated with $\mathrm{Glu}, \mathrm{MgCl}_{2}$ with or without $0.5 \mathrm{mM}$ PG and after the subsequent cold stress. After the pretreatments with Glu, $\mathrm{MgCl}_{2}$, or $\mathrm{PG}$ for $48 \mathrm{~h}$ at the room temperature, cold stress was performed at $4 \pm 1^{\circ} \mathrm{C}$ for additional $72 \mathrm{~h}$. $\mathrm{Hydrogen}$ peroxide and superoxide in leaves were visualized by DAB and NBT, respectively (A). Quantitative values for all the treatments are shown on the lower panel (B). F.W., fresh weight. Error bars show standard deviations $(n=3)$. Different lowercase letters indicate significant differences at $0.05(P<0.05)$ levels.

\section{Effects of Cold Stress and Glutamate $+\mathrm{MgCl}_{2}$ Treatments on Reactive Oxidative Species Metabolism}

Superoxide and hydrogen peroxide $\left(\mathrm{H}_{2} \mathrm{O}_{2}\right)$ are two major types of reactive oxidative species (ROS) in plant cells. Consistent with RWC and MDA contents indicated in Figure 3, cold stress increased cellular ROS levels dramatically, while $\mathrm{Glu}+\mathrm{MgCl}_{2}$ treatments offset the effect of cold stress on ROS accumulation (Figure 7). Both superoxide and hydrogen peroxide levels were significantly higher in all the mutants than those in the wild-type leaves no matter with or without $\mathrm{Glu}+\mathrm{MgCl}_{2}$ pre-treatments (Figure 7). PG-treated seedlings also accumulated high levels of ROS, indicating the adverse role of PG on plant's cold tolerance.
Besides AOX genes, multiple antioxidant enzyme genes are also Mg-ProtoIX-inducible genes (Strand et al., 2003; Zhang et al., 2011b). As shown in Figure 8, POD, SOD, and APX, all these antioxidant enzyme activities were enhanced by the cold stress, which could be further induced by the $\mathrm{Glu}+\mathrm{MgCl}_{2}$ treatment. While these inductions were greatly compromised in all the mutants or the PG treatment (Figure 8).

Besides antioxidant enzymes, there are several non-enzymatic antioxidants important for redox equilibrium, such as AsA and glutathione (GSH; Cao et al., 2009). Interestingly, we found that neither AsA levels nor AsA/DHA (reduced ascorbic acid/dehydroascorbate) ratios (and DHAR activity) were affected by cold stress or $\mathrm{Glu}+\mathrm{MgCl}_{2}$ treatments ( $p>0.05$; Figure 9). Contrastingly, GSH level was increased and GSH/GSSG (reduced 


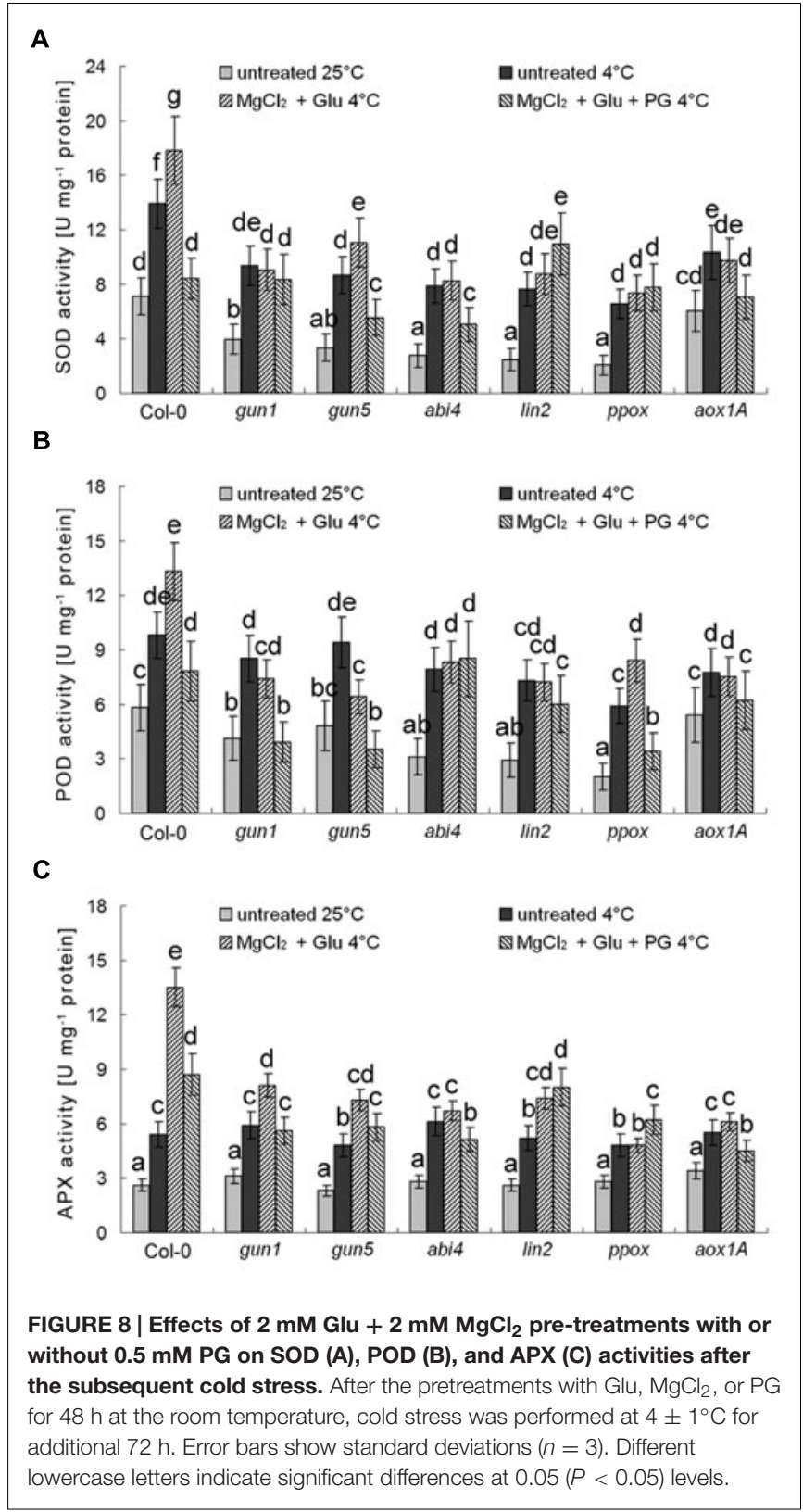

glutathione/oxidized glutathione) ratio and GR activity were significantly decreased under the cold stress, both of which could be apparently induced by the $\mathrm{Glu}+\mathrm{MgCl}_{2}$ treatment (Figure 10). These inductions by the $\mathrm{Glu}+\mathrm{MgCl}_{2}$ treatments were greatly compromised in all the mutants or after the PG treatment (Figure 10), suggesting a possible relationship between Mg-Proto IX signaling and glutathione metabolism.

\section{DISCUSSION}

Among all the mutants used in this study, abi4 mutant had the lowest transcription levels of cold-responsive genes (Figure 4). Leaf temperature is highly dependent on stomata opening (by

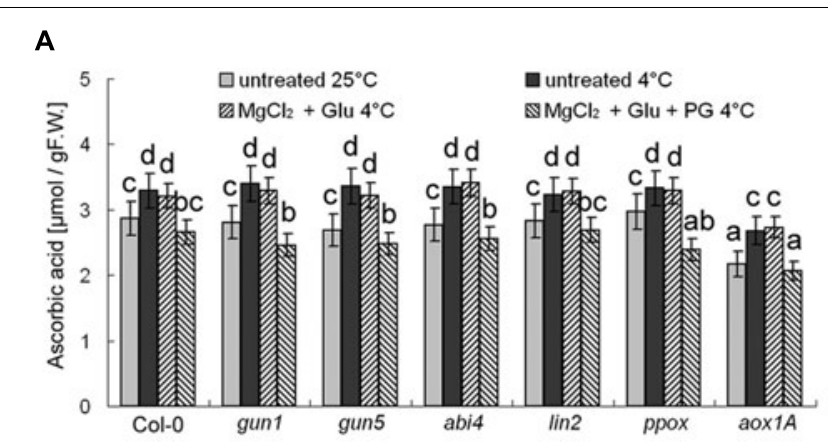

B

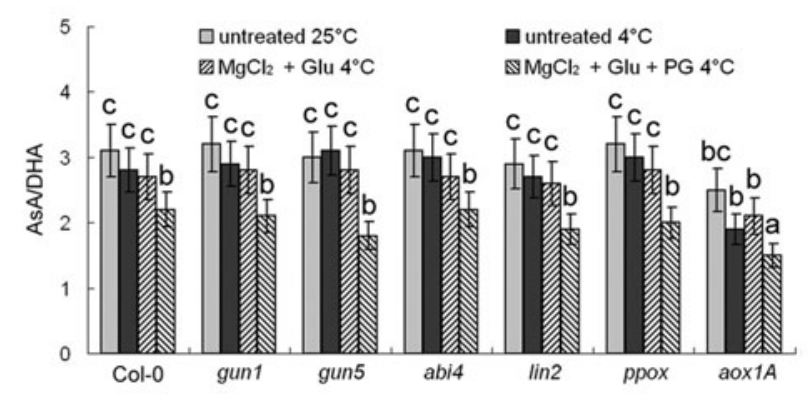

C

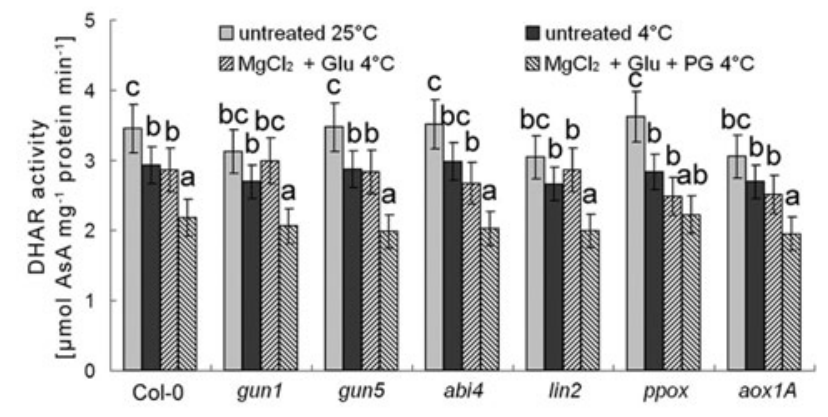

FIGURE 9 | Effects of $2 \mathrm{mM}$ Glu $+2 \mathrm{mM} \mathrm{MgCl} 2$ pre-treatments with or without $0.5 \mathrm{mM}$ PG on total AsA level (A), AsA/DHA ratio (B), and DHAR activity $(C)$ after the subsequent cold stress. After the pretreatments with Glu, $\mathrm{MgCl}_{2}$, or PG for $48 \mathrm{~h}$ at the room temperature, cold stress was performed at $4 \pm 1^{\circ} \mathrm{C}$ for additional 72 h. F.W., fresh weight. Error bars show standard deviations $(n=3)$. Different lowercase letters indicate significant differences at $0.05(P<0.05)$ levels.

influencing transpiration) and $\mathrm{ABA}$ signaling (Costa et al., 2013; Schymanski et al., 2013). Contrastingly, CBF1, CBF2, and COR15a genes showed normal responses to the cold treatment in all the mutants of either Mg-Proto IX synthesis or MgProto IX signaling (Figure 4). The results suggest that ABA signaling may be required for basic cold-response, which might be independent of Mg-Proto IX accumulation. However, MgProto IX signals further promote cold-responsive gene expression and thus enhance cold tolerance (Supplementary Figure S3). $C B F$ genes encode closely related members of the AP2/ERF family of transcription factors that recognize the C-repeat (CRT)/dehydration-responsive element (DRE) present in the promoters of CBF-targeted genes (Stockinger et al., 1997; Liu et al., 1998; Zwack et al., 2016). Constitutive over-expression of 


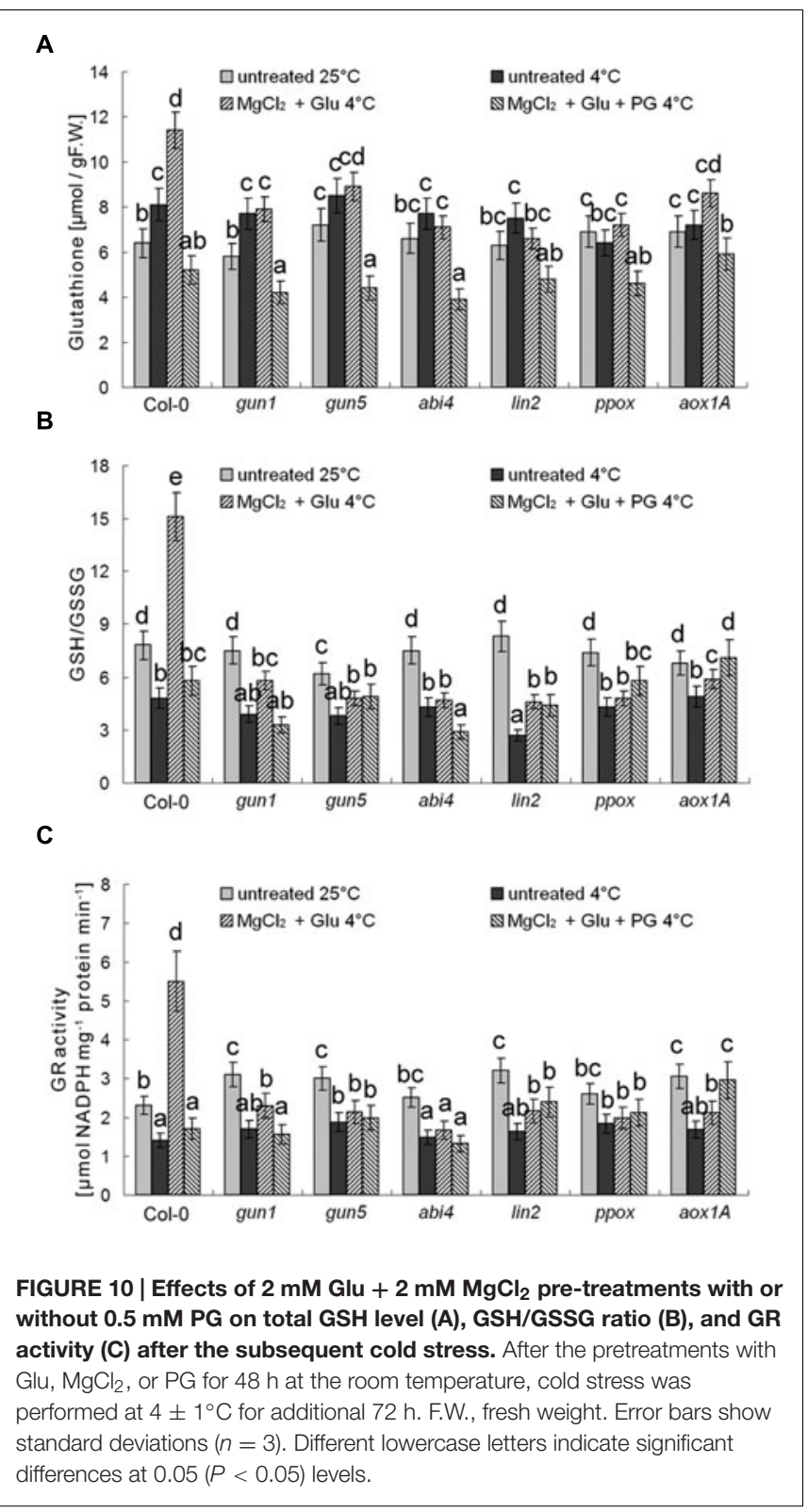

either $C B F 1, C B F 2$, or $C B F 3$ in transgenic plants leads to altered expression of about a hundred cold-regulated genes (Maruyama et al., 2004; Vogel et al., 2005), and results in an increase in cold tolerance (Liu et al., 1998; Gilmour et al., 2004). The crosstalk between ABA signaling and Mg-Proto IX signaling in the lowtemperature regulatory network needs further investigations.

There are two ubiquinol-oxidizing pathways of the respiratory chain in higher plant mitochondria. One is the $\mathrm{CP}$, which is common in the respiratory chain in all aerobic organisms, and the other is the $\mathrm{CN}$-insensitive pathway, which is charged by the AOX. The $\mathrm{CN}$-insensitive pathway branches from the main pathway after the ubiquinone and couples the ubiquinol oxidation and oxygen reduction to form water (Vanlerberghe and McIntosh, 1997). Electron transport during the oxidative phosphorylation results in a proton gradient, which drives ATP production. At the normal condition, cytochrome $\mathrm{c}$ oxidase is the terminal electron acceptor, and three ATPs are formed per oxygen molecule consumed (Roberts et al., 1984). Contrastingly, for the CN-insensitive pathway, only one ATP is formed per oxygen molecule consumed and the extra energy is released as heat (Moore and Siedow, 1991).

Thermogenic plants, such as those belonging to Araceae family, have an ability to maintain constant temperature under cold conditions (Meeuse, 1975; Watling et al., 2006). Actually, thermogenesis through the plant mitochondrial respiratory chain is significant for all plants (Watling et al., 2006; Tang et al., 2014). Our previous study showed that AOX1a gene expression was prominently induced by Mg-Proto IX signals (Zhang et al., 2011b). And then induction in CN-resistant respiration greatly enhanced plant's tolerance to the cold stress (Zhang et al., 2011b). These connections between Mg-Proto IX signals and carbon dissimilation under cold stress conditions have been further proved here by using Arabidopsis mutants. gun1, gun5, abi4, lin2, and ppox mutants developed severe hypothermia as same as the aox $1 \mathrm{~A}$ mutant, no matter with or without $\mathrm{Glu}+\mathrm{MgCl}_{2}$ pre-treatments (to induce Mg-Proto IX signals presumably). Contribution ratio of $\mathrm{CN}$-resistant respiration to the total respiration usually ranges from 20 to $50 \%$. In other words, almost a half of total C dissimilation is regulated by $\mathrm{Mg}$ Proto IX signals, which is important for plant thermogenesis during the cold exposure (Supplementary Figure S3).

Another mechanism of Mg-Proto-IX-mediated cold tolerance is the activation of enzymatic and non-enzymatic antioxidant systems. Previous studies defined some Mg-Proto-IX-signalinducible genes, including many genes related with oxidative stress, such as AOX1a, POD, SOD, APX, CAT (encoding Catalase), FH3 (encoding flavanone 3-hydroxylase), CHS (encoding chalcone synthase; Strand et al., 2003; Zhang et al., 2011b). Among non-enzymatic antioxidants, only GSH system (but not AsA system) was found here to be correlated with Mg-Proto IX-signal-enhanced cold stress tolerance.

GSH is a tripeptide with a gamma peptide linkage between the carboxyl group of the Glu side-chain and the amine group of cysteine (Cys), which is a Sulfur (thiol groups)-containing amino acid. Taken up from the soil, sulfate is incorporated into adenosine- $5^{\prime}$-phosphosulfate followed by reduction into sulfite and then sulfide and Cys biosynthesis. In parallel, adenosine-5'-phosphosulfate can be further phosphorylated to $3^{\prime}$-phosphoadenosine- $5^{\prime}$-phosphosulfate, which is used for sulfation reactions (Mugford et al., 2011). Cys is the key metabolite in the synthesis of sulfur-containing compounds in plants. While the major pool of sulfur is not stored in proteins but is the Cys-containing peptide GSH (Gigolashvili and Kopriva, 2014). GSH is a universal molecule, which plays a crucial role in plants including cellular defense, redox status balance, signal transduction and detoxification (Noctor et al., 2012; SobrinoPlata et al., 2014). Recently, GSH was shown to modulate the methylglyoxal detoxification systems during high temperature stress (Nahar et al., 2015). Here we show an explicit relationship between GSH (Sulfur metabolism) and Mg-Proto IX signals during cold stress adaptation. Although the detailed biochemical links and signal connections need further investigations. 


\section{SUMMARY}

Mg-Proto IX signals (triggered by $\mathrm{Glu}+\mathrm{MgCl}_{2}$ treatments) enhance plant's tolerance to cold stress. Both Mg-Proto IX synthesis and signaling are required for the cold tolerance. Mg-Proto IX signals prompt coldresponsive gene expression. Mg-Proto-IX-signal-induced CNresistant respiration plays a key role in heat production during the cold stress. And the reduced glutathione is also involved in Mg-Proto-IX-signal-mediated cold tolerance.

\section{AUTHOR CONTRIBUTIONS}

Z-WZ contributed all reagents and materials used in the experiments and wrote the paper. SY designed the experiments and edited the manuscript. Z-LW, L-YF, L-HD, and A-JS performed the experiments. MY, Y-EC, JZ, and G-DC analyzed the data.

\section{REFERENCES}

Cao, Y., Zhang, Z. W., Xue, L. W., Du, J. B., Shang, J., Xu, F., et al. (2009). Lack of salicylic acid in Arabidopsis protects plants against moderate salt stress. Z. Naturforsch. C 64, 231-238.

Chen, Y. E., Cui, J. M., Yang, J. C., Zhang, Z. W., Yuan, M., Song, C., et al. (2015). Biomonitoring heavy metal contaminations by moss visible parameters. J. Hazard. Mater. 296, 201-209. doi: 10.1016/j.jhazmat.2015.04.060

Cheng, J., He, C. X., Zhang, Z. W., Xu, F., Zhang, D. W., Wang, X., et al. (2011). Plastid signals confer Arabidopsis tolerance to water stress. Z. Naturforsch. C 66, 47-54. doi: 10.5560/ZNC.2011.66c0047

Costa, J. M., Grant, O. M., and Chaves, M. M. (2013). Thermography to explore plant-environment interactions. J. Exp. Bot. 64, 3937-3949. doi: $10.1093 /$ jxb/ert029

Cottage, A., Mott, E. K., Kempster, J. A., and Gray, J. C. (2010). The Arabidopsis plastid-signalling mutant gun 1 (genomes uncoupled1) shows altered sensitivity to sucrose and abscisic acid and alterations in early seedling development. J. Exp. Bot. 61, 3773-3786. doi: 10.1093/jxb/erq186

Czechowski, T., Stitt, M., Altmann, T., Udvardi, M. K., and Scheible, W. R. (2005). Genome-wide identification and testing of superior reference genes for transcript normalization in Arabidopsis. Plant Physiol. 139, 5-17. doi: 10.1104/pp.105.063743

da Silva, D. M., Brandão, I. R., Alves, J. D., de Santos, M. O., de Souza, K. R. D., and de Silveira, H. R. O. (2014). Physiological and biochemical impacts of magnesium-deficiency in two cultivars of coffee. Plant Soil 382, 133-150. doi: 10.1007/s11104-014-2150-5

Dei, M. (1985). Benzyladenine-induced stimulation of 5-aminoleuvulinic acid accumulation under various light intensities in levulinic acid-treated cotyledons of etiolated cucumber. Physiol. Plant 64, 153-160. doi: 10.1111/j.13993054.1985.tb02329.x

Elstner, E. F., and Heupel, A. (1976). Inhibition of nitrite formation from hydroxylammoniumchloride A simple assay for superoxide dismutase. Anal. Biochem. 70, 616-620. doi: 10.1016/0003-2697(76)90488-7

Gigolashvili, T., and Kopriva, S. (2014). Transporters in plant sulfur metabolism. Front. Plant Sci. 5:442. doi: 10.3389/fpls.2014.00442

Gilmour, S. J., Fowler, S. G., and Thomashow, M. F. (2004). Arabidopsis transcriptional activators $\mathrm{CBF} 1, \mathrm{CBF}$, and $\mathrm{CBF} 3$ have matching functional activities. Plant Mol. Biol. 54, 767-781.

Koussevitzky, S., Nott, A., Mockler, T. C., Hong, F., Sachetto-Martins, G., Surpin, M., et al. (2007). Signals from chloroplasts converge to regulate nuclear gene expression. Science 316, 715-719. doi: 10.1126/science.\%201140516

\section{FUNDING}

The research was financed by the National Natural Science Foundation of China (31300207 and 31201149), the Sichuan Natural Science Foundation (13ZB0296 and 014z1700) and the Preeminent Youth Fund of Sichuan Province (2015JQO045).

\section{ACKNOWLEDGMENTS}

We thank Dr. Enrique López-Juez (University of London, UK) and Prof. Joanne Chory (Salk Institute, USA) for Arabidopsis thaliana gun1 and gun5 mutant seeds. We thank LetPub (www. letpub.com) for its linguistic assistance during the preparation of this manuscript.

\section{SUPPLEMENTARY MATERIAL}

The Supplementary Material for this article can be found online at: http://journal.frontiersin.org/article/10.3389/fpls.2016.01545

Lei, T., Yan, Y. C., Xi, D. H., Feng, H., Sun, X., Zhang, F., et al. (2008). Effects of salicylic acid on alternative pathway respiration and alternative oxidase expression in tobacco calli. Z. Naturforsch. C 63, 706-712.

Lichtenthaler, H. K., and Wellburn, A. R. (1983). Determinations of total carotenoids and chlorophylls a and b of leaf extracts in different solvents. Biochem. Soc. Trans. 11, 591-593. doi: 10.1042/bst0110591

Liu, Q., Kasuga, M., Sakuma, Y., Abe, H., Miura, S., Yamaguchi-Shinozaki, K., et al. (1998). Two transcription factors, DREB1 and DREB2, with an EREBP/AP2 DNA binding domain separate two cellular signal transduction pathways in drought- and low-temperature-responsive gene expression, respectively, in Arabidopsis. Plant Cell 10, 1391-1406.

Liu, W. J., Chen, Y. E., Tian, W. J., Du, J. B., Zhang, Z. W., Xu, F., et al. (2009). Dephosphorylation of photosystem II proteins and phosphorylation of CP29 in barley photosynthetic membranes as a response to water stress. Biochim. Biophys. Acta 1787, 1238-1245. doi: 10.1016/j.bbabio.2009. 04.012

Maathuis, F. J. (2009). Physiological functions of mineral macronutrients. Curr. Opin. Plant Biol. 12, 250-258. doi: 10.1016/j.pbi.2009.04.003

Maruyama, K., Sakuma, Y., Kasuga, M., Ito, Y., Seki, M., Goda, H., et al. (2004). Identification of cold-inducible downstream genes of the Arabidopsis DREB1A/CBF3 transcriptional factor using two microarray systems. Plant J. 38, 982-993. doi: 10.1111/j.1365-313X.2004.02100.x

Meeuse, B. J. (1975). Thermogenic respiration in aroids. Annu. Rev. Plant Physiol. 26, 117-126. doi: 10.1146/annurev.pp.26.060175.001001

Miller, G., Suzuki, N., Rizhsky, L., Hegie, A., Koussevitzky, S., and Mittler, R. (2007). Double mutants deficient in cytosolic and thylakoid ascorbate peroxidase reveal a complex mode of interaction between reactive oxygen species, plant development, and response to abiotic stresses. Plant Physiol. 144, 1777-1785. doi: 10.1104/pp.107.101436

Mochizuki, N., Tanaka, R., Tanaka, A., Masuda, T., and Nagatani, A. (2008). Tetrapyrrole profiling in Arabidopsis seedlings reveals that retrograde plastid nuclear signaling is not due to Mg-protoporphyrin IX accumulation. Proc. Natl. Acad. Sci. U.S.A. 105, 15178-15183. doi: 10.1073/pnas.08030 54105

Mock, H. P., and Grimm, B. (1997). Reduction of uroporphyrinogen decarboxylase by antisense RNA expression affects activities of other enzymes involved in tetrapyrrole biosynthesis and leads to light-dependent necrosis. Plant Physiol. $113,1101-1112$.

Moore, A. L., and Siedow, J. N. (1991). The regulation and nature of the cyanideresistant alternative oxidase of plant mitochondria. Biochim. Biophys. Acta 1059, 121-140. doi: 10.1016/S0005-2728(05)80197-5 
Mugford, S. G., Lee, B. R., Koprivova, A., Matthewman, C., and Kopriva, S. (2011). Control of sulfur partitioning between primary and secondary metabolism. Plant J. 65, 96-105. doi: 10.1111/j.1365-313X.2010.04410.x

Nahar, K., Hasanuzzaman, M., Alam, M. M., and Fujita, M. (2015). Exogenous glutathione confers high temperature stress tolerance in mung bean (Vigna radiata $\mathrm{L}$.) by modulating antioxidant defense and methylglyoxal detoxification system. Environ. Exp. Bot. 112, 44-54. doi: 10.1016/j.envexpbot.2014.12.001

Noctor, G., Mhamdi, A., Chaouch, S., Han, Y., Neukermans, J., Marquez-Garcia, B., et al. (2012). Glutathione in plants: an integrated overview. Plant Cell Environ. 35, 454-484. doi: 10.1111/j.1365-3040.2011.02400.x

Park, S., Lee, C. M., Doherty, C. J., Gilmour, S. J., Kim, Y. S., and Thomashow, M. F. (2015). Regulation of the Arabidopsis CBF regulon by a complex lowtemperature regulatory network. Plant J. 82, 193-207. doi: 10.1111/tpj.12796

Phung, T. H., Jung, H. I., Park, J. H., Kim, J. G., Back, K., and Jung, S. (2011). Porphyrin biosynthesis control under water stress: sustained porphyrin status correlates with drought tolerance in transgenic rice. Plant Physiol. 157, 17461764. doi: 10.1104/pp.111.188276

Roberts, J. K. M., Wemmer, D., and Jardetzky, O. (1984). Measurements of mitochondrial ATPase activity in maize root tips by saturation transfer $31 \mathrm{P}$ nuclear magnetic resonance. Plant Physiol. 100, 1087-1091.

Schymanski, S. J., Or, D., and Zwieniecki, M. (2013). Stomatal control and leaf thermal and hydraulic capacitances under rapid environmental fluctuations. PLoS ONE 8:e54231. doi: 10.1371/journal.pone.0054231

Seymour, R. S., and Gibernau, M. (2008). Respiration of thermogenic inflores-cences of Philodendron melinonii: natural pattern and responses to experimental temperatures. J. Exp. Bot. 59, 1353-1362. doi: 10.1093/jxb/ern042

Sobrino-Plata, J., Meyssen, D., Cuypers, A., Escobar, C., and Hernández, L. E. (2014). Glutathione is a key antioxidant metabolite to cope with mercury and cadmium stress. Plant Soil 377, 369-381. doi: 10.1007/s11104-013-2006-4

Steponkus, P. L., Uemura, M., Joseph, R. A., Gilmour, S. J., and Thomashow, M. F. (1998). Mode of action of the COR15a gene on the freezing tolerance of Arabidopsis thaliana. Proc. Natl. Acad. Sci. U.S.A. 95, 14570-14575. doi: 10.1073/pnas.95.24.14570

Stockinger, E. J., Gilmour, S. J., and Thomashow, M. F. (1997). Arabidopsis thaliana CBF1 encodes an AP2 domain-containing transcriptional activator that binds to the C-repeat/DRE, a cis-acting DNA regulatory element that stimulates transcription in response to low temperature and water deficit. Proc. Natl. Acad. Sci. U.S.A. 94, 1035-1040. doi: 10.1073/pnas.94.3.1035

Strand, Å, Asami, T., Alonso, J., Ecker, J. R., and Chory, J. (2003). Chloroplast to nucleus communication triggered by accumulation of $\mathrm{Mg}$-protoporphyrin IX. Nature 421, 79-83. doi: 10.1038/nature01204

Sun, C. H., Liu, L. C., Tang, J. Y., Lin, A. H., Zhang, F. T., Fang, J., et al. (2011). RLIN1, encoding a putative coproporphyrinogen III oxidase, is involved in lesion initiation in rice. J. Genet. Genomics 38, 29-37. doi: 10.1016/j.jcg.2010.12.001

Tang, H., Zhang, D. W., Yuan, S., Zhu, F., Xu, F., Fu, F. Q., et al. (2014). Plastid signals induce ALTERNATIVE OXIDASE expression to enhance the cold stress tolerance in Arabidopsis thaliana. Plant Growth Regul. 74, 275-283. doi: 10.1007/s10725-014-9918-8

Vanlerberghe, G. C., and McIntosh, L. (1997). Alternative oxidase: from gene to function. Ann. Rev. Plant Physiol. Plant Mol. Biol. 48, 703-734. doi: 10.1146/annurev.arplant.48.1.703

Velikova, V., Yordanov, I., and Edreva, A. (2000). Oxidative stress and some antioxidant systems in acid rain-treated bean plants: protective role of exogenous polyamines. Plant Sci. 151, 59-66. doi: 10.1016/S01689452(99)00197-1
Vogel, J. T., Zarka, D. G., Van Buskirk, H. A., Fowler, S. G., and Thomashow, M. F. (2005). Roles of the CBF2 and ZAT12 transcription factors in configuring the low temperature transcriptome of Arabidopsis. Plant J. 41, 195-211. doi: 10.1111/j.1365-313X.2004.02288.x

Voigt, C., Oster, U., Börnke, F., Jahns, P., Dietz, K. J., Leister, D., et al. (2010). Indepth analysis of the distinctive effects of norflurazon implies that tetrapyrrole biosynthesis, organellar gene expression and ABA cooperate in the GUNtype of plastid signaling. Physiol. Plant 138, 503-519. doi: 10.1111/j.13993054.2009.01343.x

Watling, J. R., Robinson, S. A., and Seymour, R. S. (2006). Contribution of the alternative pathway to respiration during thermogenesis in flowers of the sacred lotus. Plant Physiol. 140, 1367-1373. doi: 10.1104/pp.105.075523

Xu, F., Zhang, D. W., Wang, J. H., Zhang, Z. W., Wen, L., Du, J. B., et al. (2012). n-propyl gallate is an inhibitor to tomato fruit ripening. J. Food Biochem. 36, 657-666. doi: 10.1111/j.1745-4514.2011.00580.x

Yang, Y., Qi, M., and Mei, C. (2004). Endogenous salicylic acid protects rice plants from oxidative damage caused by aging as well as biotic and abiotic stress. Plant J. 40, 909-919. doi: 10.1111/j.1365-313X.2004.02267.x

Yuan, S., Zhang, Z. W., Zheng, C., Zhao, Z. Y., Wang, Y., Feng, L. Y., et al. (2016). Arabidopsis cryptochrome 1 functions in nitrogen regulation of flowering. Proc. Natl. Acad. Sci. U.S.A. 113, 7661-7666. doi: 10.1073/pnas.1602 004113

Zhang, D. W., Yuan, S., Xu, F., Zhu, F., Yuan, M., Ye, H. X., et al. (2016). Light intensity affects chlorophyll synthesis during greening process by metabolite signal from mitochondrial alternative oxidase in Arabidopsis. Plant Cell Environ. 39, 12-25. doi: 10.1111/pce.12438

Zhang, Z. W., Feng, L. Y., Cheng, J., Tang, H., Xu, F., Zhu, F., et al. (2013). The roles of two transcription factors, ABI4 and CBFA, in ABA and plastid signalling and stress responses. Plant Mol. Biol. 83, 445-458. doi: 10.1007/s11103-0130102-8

Zhang, Z. W., Yuan, S., Feng, H., Xu, F., Cheng, J., Shang, J., et al. (2011a). Transient accumulation of $\mathrm{Mg}$-protoporphyrin IX regulates expression of PhANGs - new evidence for a signaling role of tetrapyrroles in mature Arabidopsis plants. J. Plant Physiol. 168, 714-721. doi: 10.1016/j.jplph.2010.10.016

Zhang, Z. W., Yuan, S., Xu, F., Yang, H., Chen, Y. E., Yuan, M., et al. (2011b). $\mathrm{Mg}$-protoporphyrin, haem and sugar signals double cellular total RNAs against herbicide and high-light-derived oxidative stress. Plant Cell Environ. 34, 10311042. doi: 10.1111/j.1365-3040.2011.02302.x

Zhang, Z. W., Zhang, G. C., Zhu, F., Zhang, D. W., and Yuan, S. (2015). The roles of tetrapyrroles in plastid retrograde signaling and tolerance to environmental stresses. Planta 242, 1263-1276. doi: 10.1007/s00425-015-2384-3

Zwack, P. J., Compton, M. A., Adams, C. I., and Rashotte, A. M. (2016). Cytokinin response factor 4 (CRF4) is induced by cold and involved in freezing tolerance. Plant Cell Rep. 35, 573-584. doi: 10.1007/s00299-015-1904-8

Conflict of Interest Statement: The authors declare that the research was conducted in the absence of any commercial or financial relationships that could be construed as a potential conflict of interest.

Copyright (c) 2016 Zhang, Wu, Feng, Dong, Song, Yuan, Chen, Zeng, Chen and Yuan. This is an open-access article distributed under the terms of the Creative Commons Attribution License (CC BY). The use, distribution or reproduction in other forums is permitted, provided the original author(s) or licensor are credited and that the original publication in this journal is cited, in accordance with accepted academic practice. No use, distribution or reproduction is permitted which does not comply with these terms. 